\title{
Mycelial growth of Philippine mushroom Lentinus tigrinus in selected cucurbit-based media and its antioxidant activity
}

Efraim Jose Liwanag, Rich Milton Dulay*, Sofronio Kalaw

Bioassay Laboratory, Department of Biological Sciences, College of Arts and Sciences, Central Luzon State University, Science City of Munoz, Nueva Ecija, Philippines

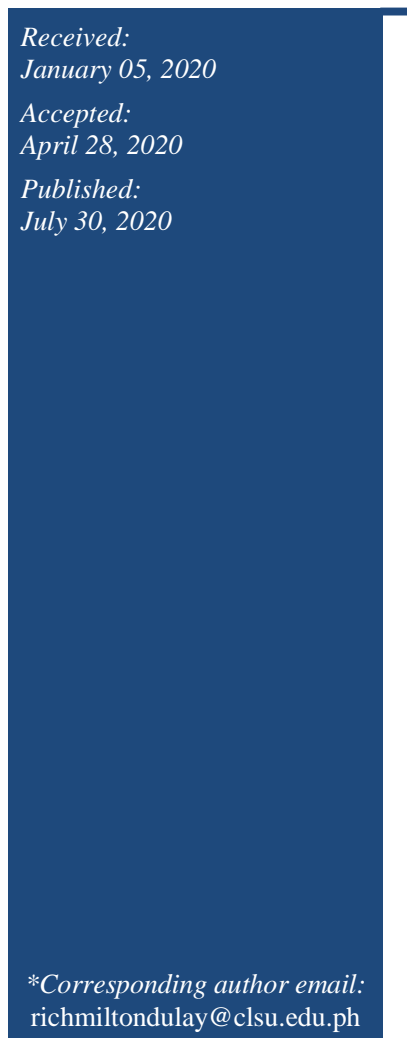

\begin{abstract}
Lentinus tigrinus, a basidiomyceteous fungus, is known to be nutritious and exhibits biological activities. The mycelial growth performance of L. tigrinus on selected cucurbit-based solid and liquid media, the ability to scavenge 2,2'diphenyl-11picrylhydrazyl (DPPH) free radicals, and the phenolic content of ethanolic extract of mycelia were investigated. Squash decoction gulaman (local crude agar) recorded the widest mycelial diameter $(71.99 \mathrm{~mm})$ regardless of the amount. However, $500 \mathrm{~g} / \mathrm{L}$ of all cucurbit species registered the widest colony diameter of $73.35 \mathrm{~mm}$. In liquid culture, both squash decoction and luffa decoction showed the highest mycelial biomass ( $0.09 \mathrm{~g}$ dry wt.). The highest mycelial biomass $(0.14 \mathrm{~g}$ dry wt.) was noted at $500 \mathrm{~g} / \mathrm{L}$ of all broth media. Extract of mycelia grown in winter melon decoction showed the highest scavenging activity (51.56\%) and phenolic content (25.04 mg GAE/g sample). Therefore, decoction of the cucurbit fruits could be used as main ingredient of culture media for efficient production of mycelial biomass and improvement of antioxidant properties of L. tigrinus.
\end{abstract}

Keywords: L. tigrinus, Cucurbit fruits, Antioxidants, Phenolics, Submerged culture

\section{How to cite this:}

Liwanag EJ, Dulay RM and Kalaw SP, 2020. Mycelial growth of Philippine mushroom Lentinus tigrinus in selected cucurbit-based media and its antioxidant activity. Asian J. Agric. Biol. 8(3): 323-329. DOI: https://doi.org/10.35495/ajab.2019.12.577

This is an Open Access article distributed under the terms of the Creative Commons Attribution 3.0 License. (https://creativecommons.org/licenses/by/3.0), which permits unrestricted use, distribution, and reproduction in any medium, provided the original work is properly cited.

\section{Introduction}

Lentinus tigrinus, also known as Kabuteng tigre among Filipinos, is an edible fungus that is usually seen growing on decaying logs, stumps, fence posts, and trunks of dead trees. The mycelia of this mushroom have been successfully domesticated and the optimum culture conditions have been established (Dulay et al., 2012). Liquid cultivation of L. tigrinus mycelia using juices of selected tropical fruits such as coconut water, watermelon, honeydew, and grapes
(Dulay et al., 2017a), and decoctions of carbohydraterich indigenous sources including rice bran, corn grit, and potato (Dulay et al., 2015a) have been demonstrated in our laboratory. These culture media significantly influenced the production of mycelia and antioxidant properties of L. tigrinus. Moreover, $L$. tigrinus contains carbohydrates, proteins, dietary fibers, reducing sugars, fats, and minerals, and its lyophilized water extract demonstrates blood glucoselowering effect in alloxan-induced mice (Dulay et al., 2014). Furthermore, Dulay et al. (2017b) reported that 
extracts of L. tigrinus also show antioxidant and antibacterial activities. Reyes et al. (2013) reported the anti-inflammatory property of this mushroom as shown by inhibition of IL-8 gene expression. It has also been reported that this mushroom has mycoaccumulation potential of heavy metals (Soriano et al., 2017).

In our search for alternative media for liquid cultivation and biomass production of L. tigrinus, cucurbits were identified in the present work. Cucurbits (Cucurbitaceae) fruits are distinctly characterized by a cylindrically green fruit with thin rind when young and become thicker as they mature, with extremely diverse shape and size but with appropriate ratio of length and diameter of fruit (Bisognin, 2002). In Central Luzon, Philippines, cucurbits such as squash (Cucurbita maxima), luffa (Luffa cylindrica), bottle gourd (Lagenaria siceraria), and winter melon (Benincasa hispida) are commonly cultivated by vegetable farmers. Aside from additional source of income, cucurbit farming also provides nutritious foods for Filipinos, as they consumed cucurbit fruits as fresh salads, pickles, vegetable soups, and as among other native vegetable dishes. As nutritious food, they contain valuable nutrients and bioactive compounds. For instance, squash, irrespective of cultivars, has high beneficial fiber and minerals (Czech et al., 2018), whereas luffa contains compounds like phenolics, triterpenoids, ascorbic acids, oleanolic acid, carotenoids, flavonoids, $\alpha$-tocopherol, chlorophylls, and ribosomeinactivating proteins (Azeez et al., 2013). These bioactive components are highly effective as immunostimulant, anti-inflammatory, anti-diabetic, antitumor, antiviral and oxytocic (Azeez et al., 2013). Kumar et al. (2012) mentioned that bottle gourd has high amounts of carbohydrates, proteins, fats, fibers, calcium, and magnesium, while Al-Snafi (2013) stated that winter melon is rich in saccharides, proteins, carotenes, vitamins, and minerals. Moreover, some cucurbits have also been reported to exhibit anthelmintic, emetic, and purgative properties (Robinson and Decker-Walters, 1997). It is hypothesized that the above-mentioned nutrients are important for the efficient growth of mycelia and could contribute to the nutritional value and functional activities of mushrooms.

Given the rich nutritional status of cucurbits, it is therefore necessary to determine the effect of decoction of selected cucurbits at varying amounts on the mycelial growth of $L$. tigrinus on both solid and liquid culture conditions. It is also of significant interest to determine the antioxidant properties of the extract of the harvested mycelia grown in liquid culture.

\section{Material and Methods}

\section{Culture}

Mycelia blocks were inoculated on potato dextrose agar plates and incubated for seven days. After incubation, a $10 \mathrm{~mm}$-diameter cork borer was used to prepare the mycelial discs as inoculants in the evaluation of mycelia growth.

\section{Preparation of solid and liquid cucurbit-based media}

The cucurbits (squash, luffa, bottle gourd, and winter melon) were purchased from the local market. These were peeled, washed, chopped, and weighed at different amounts $(100 \mathrm{~g}, 250 \mathrm{~g}$, and $500 \mathrm{~g})$. Each amount was boiled into $1 \mathrm{~L}$ distilled water and the decoction was filtered using cheesecloth. A $500 \mathrm{~mL}$ of decoction was reboiled and $10 \mathrm{~g}$ of gulaman (agar) was added. This was dispensed into a dry clean 1Lcapacity flask. On the other hand, in preparing liquid media, $50 \mathrm{ml}$ (from the remaining $500 \mathrm{~mL}$ decoction) decoction was dispensed into a glass bottle. Ten bottles were prepared for each decoction. Media were autoclaved for $30 \mathrm{~min}$ at $15 \mathrm{psi}$ and $121^{\circ} \mathrm{C}$. Flask media were pour-plated into sterilized petri plates in triplicate and allowed to solidify prior to inoculation.

\section{Evaluation of mycelial growth}

Both solid and liquid cucurbit-based media were aseptically inoculated with the mycelial disc. After five days of incubation at $30^{\circ} \mathrm{C}$, mycelial growth diameter was measured using a Vernier caliper. The optimum amount of cucurbit and the best cucurbit type were determined based on the colony diameter and density of mycelia. On the other hand, inoculated culture bottles were incubated for 15 days in a static condition at $30^{\circ} \mathrm{C}$. The mycelia were harvested, air dried, and weighed. The best cucurbit type and amount were identified based on the dry weight of mycelial biomass. The air-dried mycelia from the best concentration of each cucurbit were pulverized prior to extraction.

\section{Determination of antioxidant property}

Five grams of the pulverized samples were extracted in $300 \mathrm{~mL}$ of $95 \%$ ethanol and concentrated in a rotary evaporator until dryness and were prepared for the 
assay. The ability of the extracts as scavengers of 2, 2'diphenyl-1-1picrylhydrazyl (DPPH) free radicals was determined following the procedure of Kolak et al. (2006) with minor modifications. However, phenolic content was estimated using the FolinCiocalteu method of Sunita and Dhananjay (2010).

\section{Statistical analysis}

The SAS System Version 9.0 (SAS Institute Inc. Cary, NC, USA) was used to analyze and compare all the data.

\section{Results}

Mycelial growth and biomass production in cucurbit-based media

The mycelial diameter of L. tigrinus grown on selected cucurbit-based solid media after five days of incubation is presented in Table 1. It can be seen that from among solid media, squash decoction gulaman recorded the widest mycelial diameter, whereas bottle gourd gulaman had the smallest. In terms of the amount, $500 \mathrm{~g} / \mathrm{L}$ showed the widest mycelial diameter, while $100 \mathrm{~g} / \mathrm{L}$ registered the smallest. Tukey's HSD revealed a significant difference among cucurbit types and cucurbit amounts. At $500 \mathrm{~g} / \mathrm{L}$ of all media produced very thick mycelial density except bottle gourd gulaman (Figure 1). However, the mycelial diameter and mycelial density of L. tigrinus were improving in increasing amount of all cucurbits decoction media.

Table-1. Colony diameter of mycelia of L. tigrinus grown on selected cucurbit-based solid media on the $5^{\text {th }}$ day of incubation.

\begin{tabular}{|l|c|c|c|c|}
\hline \multirow{2}{*}{ Solid Media } & \multicolumn{4}{|c|}{ Diameter of Mycelial Growth $\mathbf{( m m} / \mathbf{5}$} \\
& \multicolumn{5}{|c|}{$\begin{array}{c}\text { days } \\
\end{array}$} & $\mathbf{1 0 0} \mathbf{g} / \mathbf{L}$ & $\mathbf{2 5 0} \mathbf{g} / \mathbf{L}$ & $\mathbf{5 0 0} \mathbf{g} / \mathbf{L}$ & Mean \\
\hline Squash & 64.97 & 72.87 & 78.14 & $71.99^{\mathrm{a}}$ \\
\hline Luffa & 66.34 & 69.41 & 70.48 & $68.74^{\mathrm{b}}$ \\
\hline Bottle gourd & 60.18 & 64.28 & 71.85 & $65.44^{\mathrm{c}}$ \\
\hline Winter melon & 61.34 & 69.87 & 72.91 & $68.04^{\mathrm{b}}$ \\
\hline Mean & $63.21^{\mathrm{c}}$ & $69.11^{\mathrm{b}}$ & $73.35^{\mathrm{a}}$ & - \\
\hline
\end{tabular}

Means with similar letter superscript indicate no statistical difference $(p<0.05)$.

The effect of selected cucurbit-based liquid media on the mycelial production of L. tigrinus was also evaluated. Table 2 shows the mean dry weight of mycelial biomass after 15 days of incubation. Both squash decoction and luffa decoction recorded the highest mycelial dry weight regardless of the amount.

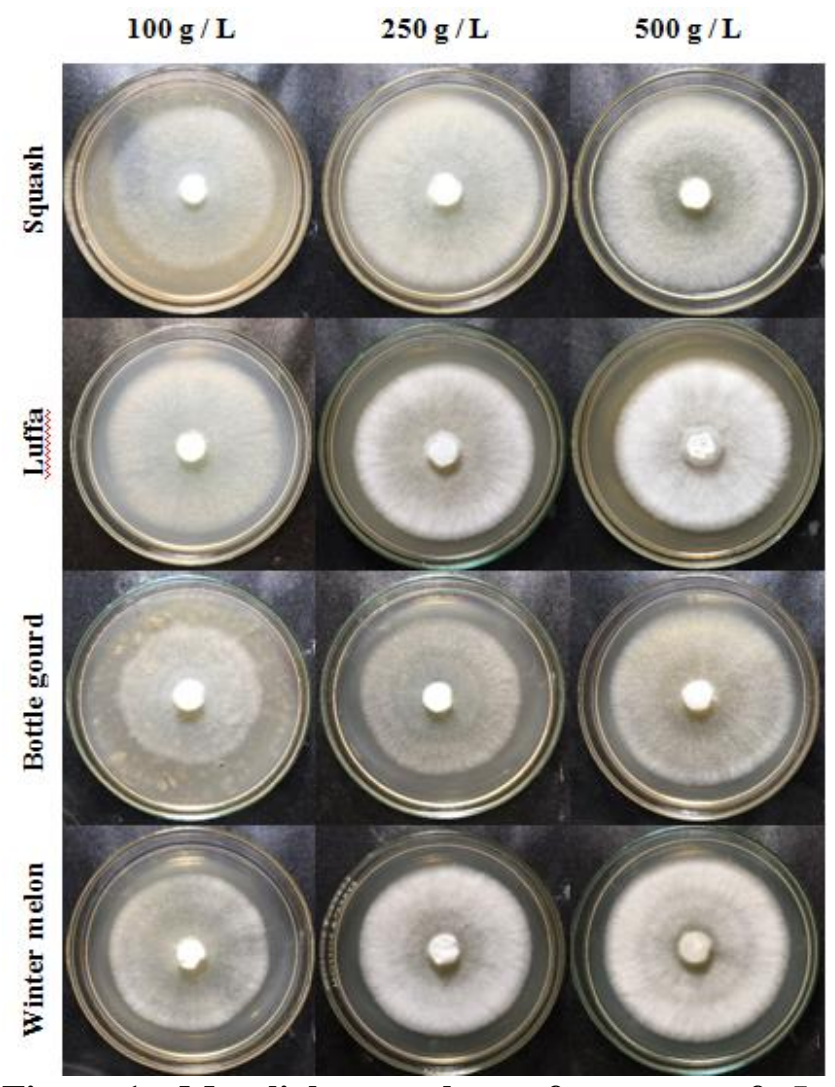

Figure-1. Mycelial growth performance of $L$. tigrinus on the varying amounts $(100 \mathrm{~g} / \mathrm{L}, 250 \mathrm{~g} / \mathrm{L}$, and $500 \mathrm{~g} / \mathrm{L}$ ) of cucurbits (squash, luffa, bottle gourd, and winter melon) after 5 days of incubation.

Table-2. Yield of mycelia of L. tigrinus cultured in selected cucurbit-based liquid media after 15 days of incubation.

\begin{tabular}{|l|c|c|c|c|}
\hline \multirow{2}{*}{ Liquid Media } & \multicolumn{5}{|c|}{ Yield of Mycelial Biomass (g dry } \\
wt./15 days) \\
\cline { 2 - 5 } & $\mathbf{1 0 0} \mathbf{~ g / L}$ & $\mathbf{2 5 0} \mathbf{g} / \mathbf{L}$ & $\mathbf{5 0 0} \mathbf{g} / \mathbf{L}$ & Mean \\
\hline Squash & 0.03 & 0.08 & 0.16 & $0.09^{\mathrm{a}}$ \\
\hline Luffa & 0.03 & 0.05 & 0.18 & $0.09^{\mathrm{a}}$ \\
\hline Bottle gourd & 0.02 & 0.06 & 0.10 & $0.06^{\mathrm{b}}$ \\
\hline Winter melon & 0.04 & 0.06 & 0.10 & $0.07^{\mathrm{b}}$ \\
\hline Mean & $0.03^{\mathrm{c}}$ & $0.07^{\mathrm{b}}$ & $0.14^{\mathrm{a}}$ & - \\
\hline
\end{tabular}

Means with similar letter superscript indicate no statistical difference $(\mathrm{p}<0.05)$.

On the other hand, the lowest biomass yield was noted in bottle gourd decoction. Similar to solid media, the mycelial biomass yield increased as the amount of cucurbit increases, and so $500 \mathrm{~g} / \mathrm{L}$ had the highest biomass yield. The liquid cultures of L. tigrinus in the varying amounts of cucurbits are shown in Figure 2. 
These results indicate that the mycelial biomass production of $L$. tigrinus is dependent on the amount and type cucurbit as basal media in the liquid culture.
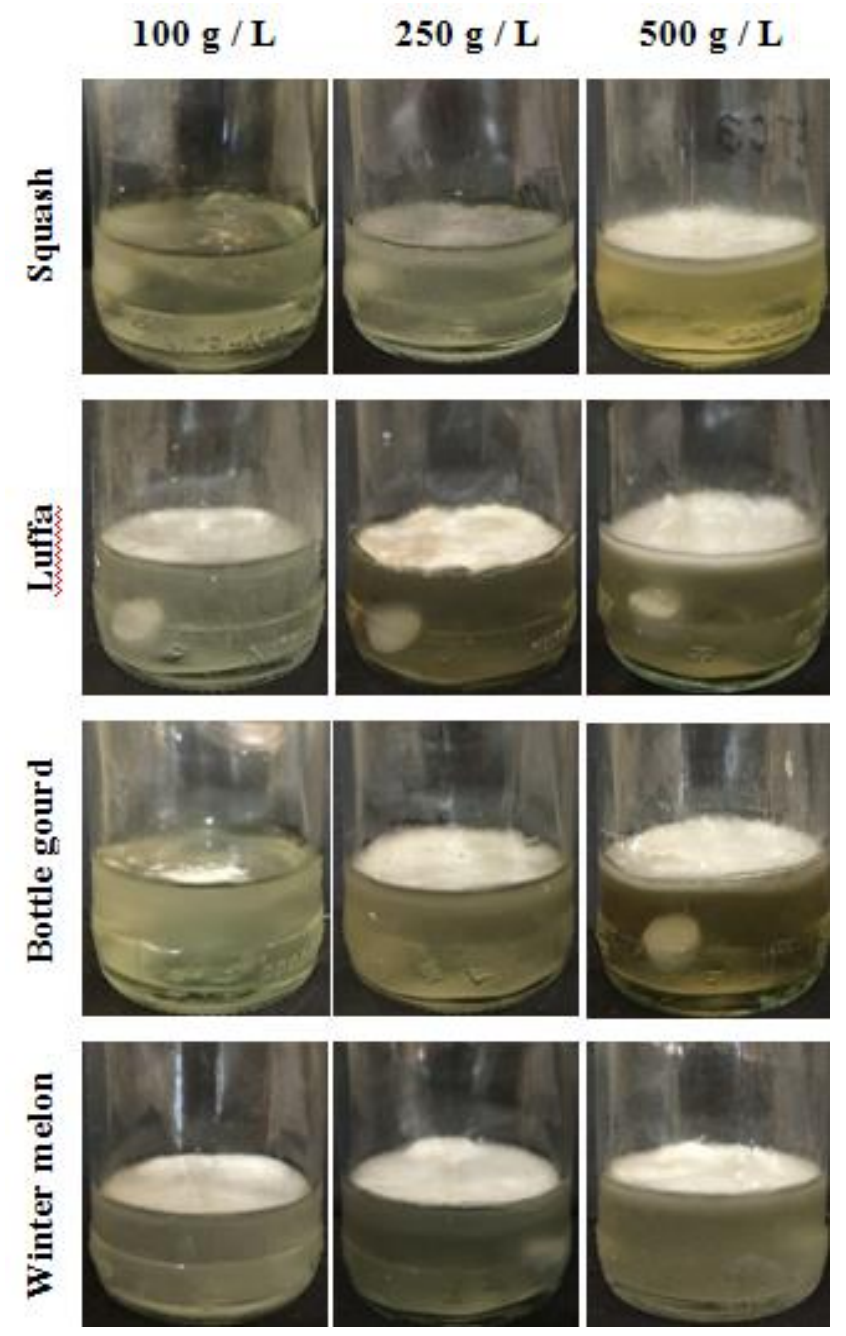

Figure-2. Liquid culture of $L$. tigrinus in the varying amounts $(100 \mathrm{~g} / \mathrm{L}, 250 \mathrm{~g} / \mathrm{L}$, and $500 \mathrm{~g} / \mathrm{L})$ of cucurbits (squash, luffa, bottle gourd, and winter melon) after 15 days of incubation.

\section{Antioxidant property of mycelia}

The percentage radical scavenging activity of the extracts of mycelia is presented in Table 3 . Apparently, the scavenging activity was significantly affected by the different cucurbit types. Extract of mycelia from winter melon decoction recorded the highest scavenging activity. This was followed by the mycelial extract from luffa decoction. On the other hand, mycelial extracts of both squash broth and bottle gourd broth registered almost the same activity. Phenolic content of the mushroom extracts was also quantified. Results of the analysis revealed that extract of mycelia grown in winter melon had the highest phenolic content, but statistically comparable with the phenolic contents of mycelial extracts from luffa decoction and bottle gourd decoction (Table 3 ).

Table-3. Antioxidant properties of ethanolic extract of $L$. tigrinus mycelia grown in selected cucurbit-based liquid media at $500 \mathrm{~g} / \mathrm{L}$.

\begin{tabular}{|l|c|c|}
\hline $\begin{array}{c}\text { Mycelia } \\
\text { grown in }\end{array}$ & $\begin{array}{c}\text { DPPH Scavenging } \\
\text { Activity (\%) }\end{array}$ & $\begin{array}{c}\text { Phenolic Content } \\
\text { (mg GAE/g sample) }\end{array}$ \\
\hline Squash & $39.84^{\mathrm{d}}$ & $18.58^{\mathrm{b}}$ \\
\hline Luffa & $43.75^{\mathrm{c}}$ & $24.42^{\mathrm{a}}$ \\
\hline Bottle gourd & $38.28^{\mathrm{d}}$ & $24.42^{\mathrm{a}}$ \\
\hline Winter melon & $51.56^{\mathrm{b}}$ & $25.04^{\mathrm{a}}$ \\
\hline Cathechin & $66.41^{\mathrm{a}}$ & - \\
\hline
\end{tabular}

Means with similar letter superscript indicate no statistical difference $(\mathrm{p}<0.05)$.

\section{Discussion}

In mushroom production, the growth performance of mycelia is dependent on the type of culture media. Mycelial biomass production in submerged cultivation or liquid culture is of greater interest than the conventional lengthy production process because the former is a fast and efficient alternative of producing biomass and metabolites (Dulay et al., 2015b). In this work, four selected cucurbit-based media at varying amounts were evaluated in both solid and liquid culture conditions. Squash decoction gulaman was found to be the most suitable cucurbit type and $500 \mathrm{~g} / \mathrm{L}$ was the optimum amount of each cucurbit for the luxuriant growth of $L$. tigrinus mycelia in both state of cultivation. The superiority of squash decoction as solid and liquid media for the growth of mycelia of $L$. tigrinus could probably be attributed to its essential chemical components. Squash contains carbohydrates, proteins, reducing sugars, amino acids, tocopherols, carotenoids, and minerals (Sharma and Rao, 2013; Adebayo et al., 2013; Czech et al., 2018; Kim et al., 2012), which are essential for physiological function. Moreover, Karanja et al. (2013) reported that squash has $\beta$ carotene (provitamin A) and fatty acids (linoleic acid, oleic acid, and palmitic acid). In our previous work (Dulay et al., 2017c), supplementation of varying amounts of vitamin A in the culture media stimulated the mycelial growths of L. tigrinus, Schizophyllum commune, and Ganoderma lucidum, and the vitamin A-enriched substrate improved the yields and 
Efraim Jose Liwanag et al.

biological efficiencies of L. tigrinus and G. lucidum. Luffa decoction was also identified as a suitable medium for mycelial biomass production in liquid culture. Luffa contains sugars and lignocellulose (Siqueira et al., 2010). Petre et al. (2016) mentioned that lignocellulose improves the growth of the mycelium through stimulation of the enzymatic activity. In addition, luffa has high amounts of essential mineral elements such as sodium, potassium, magnesium, and calcium, and rich in nutrients like sitosterol, $\beta$-tocopherol, phytol, stigmasterol, and hydrocarbons (Adewuyia and Oderinde, 2012). The above-mentioned nutrients of squash and luffa are also present in coconut water, which serve as the most suitable indigenous medium for the luxuriant mycelial growths of L. tigrinus and L. strigosus (Dulay et al., 2012; Dulay et al., 2017d). Although most of these nutrients are also components of bottle gourd and winter melon, the inferior performance of mycelia in these liquid media could probably be accounted to the presence of phenolics compounds, which are inhibitory to the normal physiology of the fungal cells, thereby affecting the growth and development of the mycelia. Pizzolitto et al. (2015) reported that some natural phenolic compounds showed inhibitory effects on the growth of fungus, Apergillus parsiticus.

Several mushrooms have been reported to exhibit antioxidants properties, which neutralize the free radicals that damage the cells resulting to aging and degenerative diseases such as cancer. These antioxidant properties of mushrooms include carotenoids, ascorbic acids, ergosterol, tocopherols, polysaccharides, and phenolics (Sanchez, 2017). In general, the physico-chemical characteristics of mushrooms are dependent on the properties and compositions of medium or substrate (Oyetayo and Ariyo, 2013). The antioxidant properties of the extracts of mycelia grown in $500 \mathrm{~g} / \mathrm{L}$ of each cucurbit were also determined in our intention to establish the effect of cucurbit-based media not only on the growth performance but also on the antioxidant activity of $L$. tigrinus. Surprisingly, the squash decoction that showed the highest yield of mycelial biomass exhibited the lowest scavenging activity and phenolic content. This observation does not conform to our hypothesis that the mycelia grown in the most suitable medium would exhibit maximum antioxidant properties. Interestingly, mycelia grown in winter melon decoction recorded the maximum antioxidant properties of L. tigrinus.
The radical scavenging activity and phenolic content of $L$. tigrinus was found dependent on the type of cucurbit. The same finding was also reported in our previous works. For instance, the scavenging activity of L. tigrinus is dependent on the type of liquid media, in which rice bran broth registered the highest radical scavenging activity (18.94\%) among indigenous liquid media (Dulay et al., 2015a). In addition, $L$. tigrinus mycelial extract from honeydew juice recorded the highest scavenging activity (79.79\%) among selected tropical fruit juices (Dulay et al., 2017a). Moreover, the maximum radical scavenging activity and phenolic content of Pleurotus djamor and G. lucidum were found in the extracts of mycelia grown in corn grit decoction and coconut water, respectively (Bustillos et al., 2018). These findings of previous and current works clearly suggest that mycelia of L. tigrinus and other mushrooms can be manipulated by the culture media to exhibit higher antioxidant properties, which indicates a significant advantage in the development of functional food and nutraceuticals.

\section{Conclusion}

Altogether, the present study has shown for the first time that decoction of the fruit of cucurbits could be utilized as alternative basal media for the efficient growth of mycelia of $L$. tigrinus in both solid and liquid culture conditions and for the enhancement of the antioxidant properties. The cultivation technique demonstrated in the present work represents significant contribution in the Philippine mushroom industry as well as in the nutraceutical and pharmaceutical industries. However, it is necessary to further elucidate other biological properties of the $L$. tigrinus extract, which are essential in the development of useful products for the benefits of mankind.

\section{Acknowledgment}

The authors would like to thank the Center for Natural Sciences, Saint Mary's University for their technical assistance in the analyses of the samples.

Disclaimer: None.

Conflict of Interest: None. Source of Funding: None. 


\section{References}

Adebayo O, Farombi A and Oyekanmi A, 2013. Proximate, mineral and anti-nutrient evaluation of pumpkin pulp (Cucurbita Pepo). IOSR J. Appl. Chem. 4(5): 25-28.

Adewuyia A and Oderinde RA, 2012. Analysis of the lipids and molecular speciation of the triacylglycerol of the oils of Luffa cylindrica and Adenopus breviflorus. CyTA - J. Food. 10(4): 313-320.

Al-Snafi AE, 2013. The pharmacological importance of Benincasa hispida: a review. Int. J. Pharma. Sci. Res. 4(12): 165-170.

Azeez MA, Bello OS and Adedeji AO, 2013. Traditional and medicinal uses of Luffa cylindrica: a review. J. Med. Plants Stud. 1(5): 102-111.

Bisognin DA, 2002. Origin and evolution of cultivated cucurbits. Ciência Rural. 32(5): 715723.

Czech A, Stępniowska A, Wiącek D, Sujak A and Grela ER, 2018. The content of selected nutrients and minerals in some cultivars of Cucurbita maxima. Br. Food J. 120(10): 2261-2269.

Bustillos RG, Francisco CS and Dulay RMR, 2018. Liquid culture and antioxidant properties of Ganoderma lucidum and Pleurotus djamor. Int. J. Biol. Pharm. Allied Sci. 7(4): 576-583.

Dulay RM, Andres SM, Asuncion AF, Calalang A and Cumbe A, 2017a. Mycelial biomass production and radical scavenging activity of Lentinus tigrinus in submerged cultivation using selected tropical fruit juice. Int. J. Biol. Pharm. Allied Sci. 6(11): 2154-2161.

Dulay RMR, Arenas MC, Kalaw SP, Reyes RG and Cabrera EC, 2014. Proximate composition and functionality of the culinary-medicinal tiger sawgill mushroom, Lentinus tigrinus (higher basidiomycetes), from the Philippines. Int. J. Med. Mushrooms. 16(1): 85-94.

Dulay RMR, Flores KS, Tiniola RC, Marquez DHH, Dela Cruz AG, Kalaw SP and Reyes RG, 2015a. Mycelial biomass production and antioxidant activity of Lentinus tigrinus and Lentinus sajorсаju in indigenous liquid culture. Mycosphere. 6(6): 659-666.

Dulay RMR, Harada HL, Santos MM, Miguel CM and Castro ME, 2017c. Mycelial growth and fruiting body performance of three Philippine edible mushrooms on vitamin a-supplemented media.
Int. J. Biol. Pharm. Allied Sci. 6(2): 308-315.

Dulay RMR, Kalaw SP, Reyes RG, Cabrera EC and Alfonso NF, 2012. Optimization of culture conditions for mycelial growth and basidiocarp production of Lentinus tigrinus (bull.) fr., a new record of domesticated wild edible mushroom in the Philippines. Philipp. Agric. Sci. 95(3): 278285.

Dulay RMR, Miranda LA, Malasaga JS, Kalaw SP, Reyes RG and Hou CT, 2017b. Antioxidant and antibacterial activities of acetonitrile and hexane extracts of Lentinus tigrinus and Pleurotus djamour. Biocatal. Agric. Biotechnol. 9(17): 141144.

Dulay RMR, Ray K and Hou CT, 2015b. Optimization of liquid culture conditions of Philippine wild edible mushrooms as potential source of bioactive lipids. Biocatal. Agric. Biotechnol. 4: 409-415.

Dulay RMR, Rivera AG and Garcia EJ, 2017d. Mycelial growth and basidiocarp production of wild hairy sawgill Lentinus strigosus, a new record of naturally occurring mushroom in the Philippines. Biocatal. Agric. Biotechnol. 10(17): 242-246.

Karanja JK, Mugendi JB, Fathiya MK and Muchugi AN, 2013. Comparative study on the nutritional value of the pumpkin, Cucurbita maxima varieties from different regions in Kenya. J Hortic. Lett. 3(1): 1-15.

Kim MY, Kim EJ, Kim YN, Choi C and Lee BH, 2012. Comparison of the chemical compositions and nutritive values of various pumpkin (Cucurbitaceae) species and part. Nutr. Res. Pract. 6(1): 21-27.

Kolak U, Özturk M, Özgokce F and Ulubelen A, 2006. Norditerpene alkaloids from Delphinium linearilobum and antioxidant activity. Phytochem. 67(19): 2170-2175.

Kumar A, Partap S, Sharma NK and Jha KK, 2012. Phytochemical, ethnobotanical and pharmacological profile of Lagenaria siceraria: a review. J. Pharmacogn. Phytochem. 1(3): 2431.

Oyetayo VO and Ariyo OO, 2013. Micro and macronutrient properties of Pleurotus ostreatus (Jacq: Fries) cultivated on different wood substrates. Jordan J. Biol. Sci. 6(3): 223-226.

Petre V, Petre M, Rusea I and Stănică F, 2016. Biotechnological recycling of fruit tree wastes by solid-state cultivation of mushrooms, pp. 19-29. In Mushroom Biotechnology: Developments and 
Efraim Jose Liwanag et al.

Applications. Academic Press, Arges County, Romania.

Pizzolitto RP, Barberis CL, Dambolena JS, Herrera JM, Zunino MP, Magnoli CE, Rubinstein HR, Zygadlo JA and Dalcero AM, 2015. Inhibitory effects of natural phenolic compounds on Asgpergillu parasiticus growth. J. Chem. Article ID 547925: 7 pages.

Reyes RG, Kalaw SP, Dulay RMR, Yoshimoto H, Miyazawa N, Seyama T and Eguchi F, 2013. Philippine native and exotic species of edible mushrooms grown on rice-straw-based formulation exhibit nutraceutical properties. Philipp. Agric. Sci. 96(2): 198-204.

Robinson RW and Decker-Walters DS, 1997. Cucurbits, Vol. 6 of Crop Production Science in Horticulture. CABI, Oxon, UK.

Sanchez C, 2017. Reactive oxygen species and antioxidant properties from mushrooms. Synth. Syst. Biotechnol. 2(1): 13-22.

Sharma S and Rao TR, 2013. Nutritional quality characteristics of pumpkin fruit as revealed by its biochemical analysis. Int. Food Res. J. 20(5): 2309-2316.
Siqueira G, Bras J and Dufresne A, 2010. Luffa cylindrica as a lignocellulosic source of fiber, microfibrillated cellulose, and cellulose nanocrystals. BioResources. 5(2): 727-740.

Soriano II, Dulay RMR and Abella EA, 2017. Mycoaccumulation of mercury by mushroom Lentinus tigrinus mycelia in liquid culture. Int. J. Biol. Pharm. Allied Sci. 6(9): 1829-1834.

Sunita M and Dhananjay S, 2010. Quantitative analysis of total phenolic content in Adhatoda vasica nees extracts. Int. J. PharmTech. Res. 2(4): 2403-2406.

\section{Contribution of Authors}

Liwanag EJ: Contributed in data collection, literature review and manuscript write up Dulay RM: Contributed in interpretation of the data, writing of manuscript and literature review Kalaw S: Contributed in data analysis and interpretation, manuscript write up and final approval 